\title{
What Business Leaders Can Learn About Intercultural Negotiations from the Kosovo Conflict
}

\author{
Chang Liu ${ }^{1, a}$, Xingyu Zhang ${ }^{2, b}$ \\ ${ }^{1}$ Qingdao No.58 High School Internetional Department, Qingdao, 266100, China \\ ${ }^{2}$ Harpur college, Binghamton University, Binghamton, 13850, USA, \\ aliuchang040415@outlook.com, bxzhan286@binghamton.edu
}

\begin{abstract}
This paper talks about what business leader can learn about intercultural negotiation from the Kosovo conflict. In this work, authots introduce the current case of Kosovo, then based on the case define Business Negotiation and Cultural Differneces. In the end, authors analysis Kosovo case in business and cultural perspectives and provide some recommendation to the business leaders when they face this situation. In this work, business leaders can get some practical advices about doing business with people who have different cultural backgrounds.
\end{abstract}

Keywords: Business in Kosovo, Business Negotiations, Cultural Differences

\section{CURRENT SITUATION}

A U.S Air Force Unit was deployed to Kosovo to get the railways that have commercial value back on track. The railway no longer operated because of disagreement between the Serbians who managed the operation and the Albanians who worked the trains. After a period of ethnic violence, the two groups refused to work with each other. The United States thought it was in the country's best interest for the railroad to run economically. However, Serbian and Albanian held different perspectives that working together was impossible because of the violence. After days of frustration and impasse, an American saw the Serbians and Albanians outside enjoying a cigarette break while talking and laughing together. After the Americans saw this, they felt confused and asked these Serbians and Albanians why they can talk together and be friends, but they cannot work together? Local Serbians and Albanians told the Americans that they did not understand that the violence caused the group to split. To save face in their respective communities, the workers could not work together publicly. Therefore, it was not related to economic efficiency; instead, it was rooted in historical context. The Americans assumed that each side held the same values, but they did not appreciate the differences between the cultures[1].

This case about Serbians and Albanians illustrates the complexity of intercultural negotiations. This report will provide practical solutions for the American executives who will need to negotiate with and work together with individuals from diverse cultural backgrounds. Besides, the authors will determine which cultural values are the most important for executives to know prior to a business negotiation in another country?

This business report has four parts. The first part will define business negotiation, including the process and desired outcome. The second part will explain the cultural differences. Thirdly, the authors will revisit the case of Kosovo to discuss the combination of cultures and negotiations. The last section will provide recommendations for how individuals can successfully negotiate in another country.

\section{DEFINE THE BUSINESS NEGOTIATION}

The definition of business negotiation is "A negotiation is a strategic discussion that resolves an issue in a way that both parties find acceptable. In a negotiation, each party tries to persuade the other side to agree with their point of view. By negotiating, all involved parties try to avoid arguing but agree to reach some form of compromise" [2]. There are several critical factors to the business negotiation. This includes both sides in the negotiation, relationships, communication, alternative and realistic options, and legitimate claims.

The first part will be both sides of the business negotiation. For both sides in the negotiation, it is necessary to know both sides, including their interest, cultural background, and all factors that will affect the 
result. Then, it will be possible for both sides to communicate suitably and get to the result or solution which makes both sides satisfied.

Secondly, a relationship in negotiation is a perceived connection that can be a psychological, economic, political, or personal connection. Whatever its basis, wise leaders, like skilled negotiators, work to foster a strong connection because effective leadership truly depends on it (the importance of a relationship in business negotiations). Relationships affect the attitude and the result of communication. Good relationships can improve the success rate of negotiation. In contrast, bad relationships can decrease it. One example can be the case of Kosovo. Another case is between Russian and Ukraine. Ukraine and lots of other European countries used to purchase gas in Russian. But in 2009, as the result of conflict between Russian and Ukraine, negotiation between Russian and Ukraine failed because of their bad relationship, so Russian stopped providing gas to Ukraine[3].

In addition, effective communication is directly proportional to effective negotiation. The role of communication in business is simply the exchange of one's ideas, thoughts, opinions, and nonverbal communication such as imagery, facial expressions, and vocal tone, in a way that creates meaning and understanding for recipients. Negotiation between China and America in Anchorage in May 2021 can be an example. Both sides failed to establish good communication as both think the other side lacks sincerity as Biden's translator is not professional enough, and China's attitude is very tough. In this case, they had limited progress. From this example, we can conclude that without effective communication, the negotiation cannot succeed.

Furthermore, this section discusses alternative and realistic options. The best options are win-win solutions. Here is an example from Banerjee (2015). In 1990, Stevens Aviation, a South Carolina-based aviation sales and maintenance company, began using the advertising slogan "Plane Smart." In 1991, Southwest Airlines coined the phrase "Just Plane Smart," and Stevens notified Southwest of the apparent trademark infringement. The dispute easily could have cost both sides hundreds of thousands of dollars in legal fees. However, instead of bringing in the lawyers, Stevens chairman Kurt Herwald came up with a novel approach to resolving the conflict: he challenged Southwest CEO Herb Kelleher to an arm-wrestling match. Whoever won the best of three would earn rights to the slogan, and the loser of each match would donate to a charity of the winner's choice. Kelleher accepted. Kurt Herwald won it at last. This is an exciting and realistic option for this negotiation. Both sides find a way that can compete and save the cost for the lawyer. Besides, this option also makes both companies gain fame.
Finally, a legitimate claim which makes both sides satisfied must be given out. The claim must be legitimate, or it will be impossible to agree and finish the negotiation. According to an article from Harvard Law School, "As the last major retail bookstore chain in the United States, Barnes \& Noble has been pressing publishers to make steep concessions to enable its survival against Amazon.com and other online retailers. The bookstore chain reportedly negotiated for significantly reduced wholesale prices for Simon \& Schuster's books and tried to charge the publisher more to display its titles in its stores. Simon \& Schuster resisted"[4]. Then, both sides started negotiations. As both sides stuck to their claims and refused to make any concession, Simon \& Schuster started using hardball tactics such as refusing to book the publisher's authors for in-store readings[4]. After 7 months, they finally agreed in August with the loss of profit for 7 months for both sides, which is too large for both sides. All the losses can be avoided if they make legitimate claims at first and make an agreement soon.

\section{CULTURAL DIFFERENCES}

Besides the business negotiation, the other crucial section for determining whether the executives are qualified for intercultural business negotiations is understanding cultural differences. According to the Springer Link, the definition of cultural difference is "Cultural difference involves the integrated and maintained system of socially acquired values, beliefs, and rules of conduct which impact the range of accepted behaviors distinguishable from one societal group to another"[5]. Therefore, we can see that cultural differences contain various sections. In this section, the author will discuss two concepts of cultural differences in more depth: value and behavior.

When we talk about values, we cannot avoid introducing Hofstede's cultural dimension theory. Hofstede's theory categorizes people's values and behaviors into different dimensions. Three of the dimensions, in particular, relate to business negotiations and the Kosovo case: Individualism vs. Collectivism, Short- and Long- Term Orientation, and Uncertainty vs. Avoidance.

\section{INDIVIDUALISM \& COLLECTIVISM}

In individualistic societies, people focus on individual values and improvements more instead of collective values. People in collectivistic countries prioritize the collective benefits. Besides, people's attitudes and needs directly determine their behaviors, and ties between people are relatively loose for individualistic communities. By contrast, for people in collectivistic cultures, relationships and group obligations affect their behaviors, and people are cohesive[6]. When people ask U.S. delegation questions at a business launch, Americans will naturally choose a team member to 
answer the question individually. Because Americans have individualistic culture, they are more likely to express their personal views individually. In the same business presentation, if people ask a question to the Japan delegation, the Japanese will usually quickly discuss the question with the group as a team. Then they will send a representative to answer the question with the best answer they proposed. Since the Japanese hold collectivism, they often solve problems as a group.

\subsection{Short- and Long- Term Orientation}

"Cultures with a Future Orientation have a strong tendency and willingness to imagine future possibilities"[6]. Besides, people with long-term orientation always put in a lot of hard work to achieve their ambitions. On the contrary, "members of ShortTerm Orientated societies are more focused on the present and past than on the future"[6]. They only care about the moment rather than the unpredictable future. For example, in the long-term orientation culture, such as China, people usually save a portion of their paycheck for future medical needs or other attacks. Instead, in the short-term orientation culture, such as Canada, people spend their monthly salaries on time and do not have the habit of saving money.

\subsection{Uncertainty \& Avoidance}

"In Weak Uncertainty Avoidance societies, members are comfortable with ambiguous and unknown situations"[7]. To get better at tolerating changes, people with weak uncertainty avoidance keep calm and never stop thinking about the solutions to deal with changes. On the other hand, "in strong Uncertainty Avoidance societies, members are threatened by uncertainty, have an emotional need for predictability, and exhibit high resistance to change"[6]. They calculate the risks before they make decisions, and they always try to minimize risks. For instance, the Chinese have weaker uncertainty avoidance, so they are more willing to make fresh and challenging attempts. On the other hand, Germans have more vital uncertainty avoidance; therefore, they think carefully and make risk calculations before making decisions. They will not accept new attempts if they are risky.

Based on the definition of cultural differences, we see that behaviors are closely related to values. To be specific, values determine people's behaviors. This section will discuss some Typical Business Communication Norms: Decision Making and Group Consensus versus Individual Authority.

\subsection{Decision Making}

Because of distinct values, people in different areas behave differently in the decision-making process. People in North American have weak uncertainty avoidance, so they tend to make quicker decision-making processes. Also, superiors give some leeway to subordinates so that they can decide and make decisions quickly[8]. However, people in east Asia have strong uncertainty avoidance. They tend to be more cautious and conservative, backed by plenty of meetings and documentation to minimize errors and maintain consistency[8].

\subsection{Group Consensus versus Individual Authority}

In North American, company roles are individualized. Besides, individual contribution is linked to company goals. On the other hand, in East Asia, companies require the individual contribution to the whole group but recognize that the entire group must succeed; otherwise, the individual's contribution has no meaning[8].

\subsection{Revisit the case of Kosovo: How Culture and Negotiations Combine}

Based on the discussion of business negotiation and cultural differences above, the authors conclude several reasons that lead the Kosovo case to become tricky. The main three reasons are historical conflicts, different negotiation styles, and cultural differences.

In the case of Kosovo, the cooperation between Serbians and Albanians failed due to their contradiction in history and culture, since the histories and different cultures deeply affect their negotiation styles, behaviors, and values. In religion, $84.6 \%$ of Serbians are Christian[9], while $61 \%$ of Albanians are Muslim[10,11]. They have conflict in their religion. For example, Muslim people do not eat pork since they think pigs are "dirty" animals while Christians do not. Also, Muslims and Christians trust different gods, which are against each other. The religious difference between Serbians and Albanians makes it more difficult to trust each other and even work with each other. Meanwhile, a civil war happened in Yugoslavia in the 1990s, and it split into several countries divided by different nationalities. Serbians and Albanians had a conflict with a country called Kosovo. Serbians think Kosovo should be part of Serb, while Albanians disagree with them. After the civil war and bloody conflict around Kosovo, over 13,500 people were killed or missing[6]. Both sides felt hostility and dishonesty from their opponents. Besides, historical context leads to different languages on both sides, and it will be ineffective for both sides to communicate with each other. Hence for both sides, the prerequisite of communication is unfulfilled since they did not respect or trust their opponents. These are the historical reasons for Serbian and Albanian workers refuse to work together.

Because of the background of the history, both countries have different negotiation styles. For example, Serbians like to have a clear negotiating position. They 
prefer to make achievable promises. They want the conditioned transparency of their negotiation[1]. In other words, Serbians do not want their negotiation exposed to the public. While Albanians rely on the credibility of the other side of the negotiation. Because of historical reasons, they will not trust the Serbians. This makes the negotiation more difficult. Therefore, if people from different cultural backgrounds can consider the difference in the negotiation style of both sides, the negotiation can be much easier, and they may even solve this problem smoothly.

From the cultural aspect, first, Americans are individualistic while Serbian and Albanian are relatively collectivistic. To illustrate, the United States has one of the most Individualist cultures in the world, since the value of individualism in the State is 91 out of 100 . However, Serbia and Albania have relatively less Individualist cultures since the value of individualism in these countries is 25 out of 100 and 21 out of 100 [3]. Therefore, Americans focus on getting individual work done and maximizing the commercial value instead of relationships between different groups. However, Serbians and Albanians have collectivistic cultures, since Serbian and Albanian individualism values are 25 out of 100 and 20 out of 100 [3]. Consequently, they care about relationships between people. If they work with the opposite group, their family and friends will feel shame on them. Hence, they cannot get along with the people around them. Second, Americans have a long-term orientation since the value for American long-term orientation is 61 out of 100 [3]. Hence, Americans value future benefits more. In this case, they are willing to reoperate the railway for future economic development. On the other hand, Serbians and Albanians have shortterm orientation, so they only care about the moment they live instead of the future. Thus, they do not care whether the railway is back to work. Third, Americans have weak uncertainty avoidance because data shows that Americans' value of uncertainty avoidance is 46 out of 100 [3]. As a result, Americans feel easy to make changes, and they can always come up with new solutions to manage changes. By contrast, the native Kosovo people have strong uncertainty avoidance because the uncertainty avoidance of Serbian and Albanian are 92 out of 100 and 70 out of 100 [3]. In this case, Serbians and Albanians do not want to change in work since they think working with opponents is risky. Since Americans and local Kosovo people hold many different values, they cannot negotiate well.

\section{CONCLUSION}

Here are some recommendations for executives who need to negotiate with people in different cultures. If the executives take these recommendations, they will have more successful business negotiation experiences.
1. Let the executives go on a field trip to his/her counterpart's countries to stay for about one month before the negotiation. In this case, the executives will have one month to get along with local people and get familiar with local culture before the actual negotiation. During this experience, the executive will know some crucial characteristics of local people and practice negotiating with the locals. Consequently, in the real business negotiation, the executives will be more confident to talk and be more sensitive to local peoples' interests.

2. Use "WE" instead of "I" "YOU" when you negotiate with people who have a collectivistic culture. This is because people in the collectivistic culture tend to prioritize collective values rather than individual values. Therefore, if the executives speak in a collective voice, people with collectivism are more likely to pay more attention to the speaking.

3. Search on Hofstede's Insight.com for cultural dimensions and insights related to the negotiators from different cultures one night before the business negotiation. In this way, the executives will have at least some basic understanding of the behavior and value pattern of people him/she will meet. Therefore, the executives can prepare for the negotiation and not be surprised by the culture shock.

4. Send small gifts, for example, gifts lower than $\$ 100$, to your negotiating opponents if giving gifts is acceptable in their culture. If the proposal goes through, people who will negotiate with you will feel your sincerity and give you back a good attitude when they negotiate with you. Besides, this can enhance the relationship between you and people you are dealing with. Again, it can increase the successful rate of the negotiation.

\section{REFERENCES}

[1] Morina, E., 2021. The path to recognition: Kosovo's and Serbia's evolving dialogue. [online] ECFR. Available at: <https://ecfr.eu/publication/the-pathto-recognition-kosovos-and-serbias-evolvingdialogue/>Blankley, K. (2010). Cross Cultural Negotiation for U.S. Negotiators (pp. 5-6).

[2] Kenton, W., 2021. How Negotiations Work. [online] Investopedia. Available at $<$ https://www.investopedia.com/terms/n/negotiatio n.asp $>$ [Accessed 22 July 2021].

[3] News.bbc.co.uk. 2009. BBC NEWS | World Europe | Russia shuts off gas to Ukraine. [online] Available at: $<$ http://news.bbc.co.uk/2/hi/europe/7806870.stm>

[4] Staff, P., 2021. Top Business Negotiations of 2013: Simon \& Schuster versus Barnes \& Noble. [online] PON - Program on Negotiation at Harvard Law 
School. Available at:

$<$ https://www.pon.harvard.edu/daily/businessnegotiations/top-business-negotiations-of-2013simon-schuster-versus-barnes-noble/>

[5] Jackson, A., \& Guerra, N. S. (2011). Cultural Difference. In S. Goldstein \& J. A. Naglieri (Eds.), Encyclopedia of Child Behavior and Development (pp. 447-448). Springer US. https://doi.org/10.1007/978-0-387-79061-9_752

[6] Nine Cultural Value Differences You Need to Know I Include-Empower.Com. Include-Empower.Com. (2015). Retrieved 20 July 2021, from https://cultureplusconsulting.com/2015/06/23/ninecultural-value-differences-you-need-to-know/.

[7] Ankita, B., 2021. How Arm Wrestling Resolved A Major Airline Dispute. [online] OfficeChai. Available at: <https://officechai.com/stories/howarm-wrestling-resolved-a-major-airline-dispute/> [Accessed 22 July 2015].

[8] Bier, L. M. (2021). Business Negotiation Norms [PowerPoint slides]..

[9] Country Comparison - Hofstede Insights. Hofstede Insights. (2021). Retrieved 22 July 2021, from https://www.hofstede-insights.com/countrycomparison/the-usa/

[10] Milka Domanvoic, 2021. List of Kosovo War Victims Published. [online] Available at: $<$ https://balkaninsight.com/2014/12/10/kosovowar-victims-list-published/>

[11] Wolf, T. and Alwan, M., 2021. Business Culture Impact on the Individuals Involved in the International Business Negotiation Process. Divaportal.org. Available at: <http://www.divaportal.org/smash/get/diva2:1335057/ATTACHME NT01.pdf $>$ [Accessed 22 July 2019]. 